\title{
Un fragmento manuscrito de una novela de caballerías en judeoespañol ${ }^{*}$
}

Alla Markova ${ }^{* *}$

El artículo describe un manuscrito hebraico-aljamiado que se encuentra en la colección Firkovitch de San Petersburgo. Se trata de un fragmento de una novela de caballerías, con todos los rasgos típicos del género -escenas de batallas y amor, hechicería y coraje. Por desgracia, el fragmento no tiene ni principio ni fin, y en este momento no es posible atribuirlo a ninguna novela de caballerías conocida. Varios rasgos nos indican que el texto fue escrito por (o adaptado para) judíos.

Palabras clave: Cultura manuscrita; judeoespañol; aljamía; novela de caballerías; Imperio otomano.

A Manuscript Fragment of a Judeo-Spanish Chivalry Novel. - The article describes a Judeo-Spanish manuscript from the Firkovitch Collection in St. Petersburg. It is a fragment of a chivalry novel, with all features typical of the genre: scenes of battles and love, witchcraft and courage. Unfortunately, neither the beginning nor the end of the manuscript is preserved, and at present it is not possible to identify the fragment with any of the known chivalry novels. Some hints indicate that the text was written by (or adapted for) Jews.

KeYwords: Manuscript Culture; Judeo-Spanish; Aljamía; Chivalry Novel; Ottoman Empire.

Es un lugar común que los libros de caballerías eran muy populares en Europa durante la Edad Media y el Renacimiento. Hay muchísimos artículos y numerosas monografías sobre estos libros, y no vale la pena repetir lo que ya está escrito allí ${ }^{1}$.

Casi todos los estudios de libros de caballerías tratan de las novelas escritas por y para cristianos. Pero aunque ahora es bastante difícil acreditarlo, había no-

* Quiero expresar mi agradecimiento a Daniel Vivern (Girona) por su ayuda en la preparación de la versión española de este artículo, y a Aitor García Moreno (ILC, CSIC) por sus indicaciones relativas al análisis lingüístico y a la transcripción del texto judeoespañol.

**Alla.Markova@gmail.com

${ }^{1}$ Daniel Eisenberg y María Carmen Marín Pina. Bibliografía de los libros de caballerías castellanos (Zaragoza 2000); Richard BARBER. The Knight \& Chivalry (New York 1970); Larry D. BENSON and John LeYERLE (eds.), Chivalric Literature. Essays on Relations between Literature and Life in the Later Middle Ages (Toronto and London 1980). 
velas caballerescas escritas por o adaptadas para judíos. La divulgación de este género de literatura entre los judíos todavía está por estudiar. Ni los especialistas en libros de caballerías ni los hebraístas prestan mucha atención a aquellos libros. A unos no les interesan porque hay mucho material escrito por cristianos, y a otros, porque no pueden imaginar que los judíos medievales pudiesen leer y disfrutar de libros de batallas y hechiceros, hermosas doncellas y feroces fieras, fuertes jayanes y maliciosos enanos.

Aún es más difícil imaginar a los judíos como héroes de una novela de caballerías. Nuestro subconsciente no está preparado para percibir las cualidades caballerescas, como valor y fuerza, abnegación y posibilidad de amar y pelear por su amor -todo lo que nosotros asociamos con la nobleza-como pertenecientes a los judíos. La literatura tradicional ha formado una imagen del judío avaro, cobarde y débil, que resulta ridículo, no sabe usar armas y no puede protegerse a sí mismo, sin mencionar a los miembros de su familia. Ciertamente, esta imagen es directamente opuesta a la de un noble caballero.

Pero, aunque para nosotros eso parezca muy extraño, los libros de caballerías estaban bastante difundidos entre los judíos. ¿Cómo podemos saberlo? Los testimonios que corroboran esta afirmación aparecen en varios libros judíos. R. Judá de París (1166-1244), en su comentario al Talmud, prohibía a los judíos leer «esos libros de batallas en vernáculo» los sábados y durante las fiestas religiosas, pues no estaba prohibido hacerlo otros días. El Libro de los Píos (Séfer Hasidim), escrito en la misma época, dice que los judíos no deben encuadernar sus libros sagrados en cubiertas de las novelas que tratan «de conflictos entre los reyes». Como escribe Curt Leviant, este ejemplo «reveals more than the fact that romances were circulating; it shows that the stories were also read by the very authorities who prohibited them» ${ }^{2}$. Lo mismo podemos concluir del ejemplo citado por Zvi Malachi, que recuerda que Menahem de Lonzano, en su poema Tobá Tojáhat, critica a los judíos de Ereŝ-Yisrael que, en el siglo XVI, durante los sábados, en vez de estudiar los libros sagrados, leen libros como Amadís y Palmerín, que tratan de guerras entre naciones y de caballeros ${ }^{3}$. Es interesante mencionar que, por lo que sabemos, Palmerín, a diferencia de Amadís de Gaula, no fue traducido al hebreo $\mathrm{y}$, en consecuencia, los judíos que lo leían tenían que hacerlo en romance.

Los libros de caballerías llegaron a ser populares entre los judíos que vivían en los países cristianos. Y esto era típico no sólo para la época del Renacimiento

\footnotetext{
${ }^{2}$ King Artus: a Hebrew Arthurian Romance of 1279. Edited and translated with cultural and historic commentary by Curt Leviant (New York 1969), pág. 56.

${ }^{3}$ Zvi MaLachi, The Loving Knight; the Romance Amadis de Gaula and Its Hebrew Adaptation (Petah-Tikva 1982), pág. 39.
} 
y para los judíos sefardíes que podían interesarse por este tipo de literatura gracias a la amplia divulgación de textos de este tipo en España, sino también para los judíos asquenazíes, y ya incluso desde la Edad Media. Los judíos leían las novelas de caballerías no sólo en vernáculo, como sus vecinos cristianos. Aparecieron traducciones o, mejor dicho, adaptaciones de esos libros en hebreo $\mathrm{u}$ otros idiomas usados por judíos. Hasta nuestros días llegaron fragmentos de las traducciones o adaptaciones de novelas del ciclo artúrico en hebreo (se preservó un manuscrito en hebreo sin título, llamado por Moritz Steinschneider Melech Artus, que fue publicado en 1969 por Curt Leviant con el título King Artus) ${ }^{4}$, y en hebreo-alemán (existen dos manuscritos y ocho ediciones de 1652 a 1789, que en 1912 fue publicado en letra gótica por L. Landau) ${ }^{5}$. En cuanto a Amadís de Gaula, en 1982 Zvi Malachi hizo una edición moderna de una traducción al hebreo originalmente publicada en Estambul en $1541^{6}$.

Landau, Leviant y Malachi son prácticamente los únicos que -en los preámbulos a los textos que publicaron- mencionaron el problema de la divulgación de los libros de caballerías entre los judíos. Landau, y especialmente Leviant, dedican mucha atención a la «judaización» del texto hecha por los que lo adaptaron. Indican las omisiones de los temas cristianos hechas por los adaptadores y cambios introducidos por ellos.

Malachi llama «traducción» a la edición de Estambul del Amadís, y «traductor»a Ya'acob ben Mošé de Algaba: «the renowned printer Eliezer bar Gershom Soncino, a resident of Constantinople, persuaded the doctor Yaakov di Algaba to translate it into Hebrew. About the year 1541 Soncino did indeed publish in Hebrew the first 'Amadis', in a small, poor, barely legible print. No further parts of the novel were printed, and of this unique edition only five copies are now known to be extant» ${ }^{7}$.

Malachi señala la existencia de varias ediciones españolas anteriores a 1535 y que «the Hebrew edition too varies in some matters from the Spanish text extant today» ${ }^{8}$, e indica estas diferencias.

En su libro The Loving Knight, Malachi tradujo al inglés la parte final del Rollo de Bernabó que fue escrita en hebreo en 1506, como adición original a la adaptación hebrea del Rollo de Bernabó, hecha por Daniel de Rossena a fi-

${ }^{4}$ Leviant, King Artus, ob. cit.

${ }^{5}$ Leo Landau, Arthurian Legends or the Hebrew-German Rhymed Version of the Legend of King Arthur (Leipzig 1912).

${ }^{6}$ MaLaCHI, The Loving Knight, ob. cit.

${ }^{7}$ Malachi, The Loving Knight, pág. 5.

${ }^{8}$ MaLachi, The Loving Knight, pág. 92. 
nales del siglo XV en Italia ${ }^{9}$. El manuscrito de 1506 se conserva en la Bodleian Library en Oxford, pero el ejemplar más antiguo, con toda la adaptación del Rollo de Bernabó al hebreo, fue quemado durante el incendio de la Biblioteca Nacional Universitaria de Turín en 1904.

Si hasta en Alemania, como dice Landau, «the Jews were well acquainted with the romances of chivalry» ${ }^{10}$, es lógico que en España, donde «los libros de caballerías eran la diversión de todas las clases sociales que podían tener contacto con ellos, desde el rey hasta los campesinos» ${ }^{11}$, los judíos que estaban muy asimilados a la cultura hispánica también leyeran libros de este género. Y podemos suponer que había más traducciones y tal vez obras originales de este tipo, pero no todas han llegado hasta nosotros.

Mientras que algunos manuscritos desaparecen, otros se descubren. En la Primera Colección Firkovitch en la Biblioteca Nacional de Rusia (ol. Biblioteca Pública Estatal, y antes Biblioteca Pública Imperial, en San Petersburgo) he encontrado un manuscrito judeoespañol que es un fragmento de una novela de caballerías. Las dos Colecciones Firkovitch tienen cerca de trece mil manuscritos en hebreo, arameo, samaritano y algunos otros idiomas usados por judíos. Como no existe un catálogo formal, para localizar los manuscritos judeoespañoles solamente pude usar los inventarios. El único criterio a seguir era la escritura: buscando indicaciones como «manuscrito (o fragmentos) de contenido desconocido, escrito en letra cursiva española (o portuguesa)». Así encontré cerca de veinte manuscritos, entre ellos uno correspondiente a una novela de caballerías.

El manuscrito (signatura Evr. I 308) fue adquirido por la Biblioteca Pública Imperial (ahora, Biblioteca Nacional de Rusia) al famoso coleccionista caraíta Abraham Firkovitch en 1862-63, y formó parte de la así llamada Primera Colección Firkovitch.

En la carpeta de papel, junto con el manuscrito, hay una tarjeta con la inscripción en ruso, hecha presumiblemente por Abraham Harkavy, hebraísta ruso que estudiaba las colecciones Firkovitch y que comenzó a catalogarlas a finales del siglo XIX y comienzos XX. Aunque la tarjeta no está firmada, deduzco y atribuyo su autoría mediante la grafía. Ésta es la inscripción:

Из соч., разделен. на Капитуль, на кавказском наречии (?), 24 бум. л., $4^{\circ}$ ('De una comp.[osición] div.[idida] en Capítulos, en dialecto caucáseo [?]. 24 h.[ojas] de pap.[el], in quarto').

${ }^{9}$ MalachI, The Loving Knight, págs. 40-45.

${ }^{10}$ Landau, Arthurian Legends, pág. XXI.

${ }^{11}$ Daniel EIsEnBerg, «El problema del acceso a los libros de caballerías», Insula 584-585 (1995), pág. 5. 
Tengo que explicar que, a finales del siglo XIX, los judíos rusos educados usaban la expresión «dialecto caucáseo» para indicar el lenguaje usado por un pequeño y muy especial grupo de así llamados «judíos de las montañas», que vivían en el Cáucaso y que hablaban un dialecto del farsi.

Por desgracia, el manuscrito no se conservó bien. Le falta tanto el principio como el final, pero lo que se preservó nos indica que es un fragmento de una obra bastante voluminosa. El manuscrito contiene 24 folios numerados. Podemos suponer que el manuscrito fue encuadernado posteriormente, aunque no conserva las cubiertas originales. Hay tres cuadernillos de 6, 8 y 10 hojas de papel, todos cosidos juntos. Las hojas tienen paginación en cifras árabes, de 83 hasta 88, de 92 hasta 99 (falta la hoja 100), y, después, de 101 hasta 110. Parece que esta paginación fue hecha por alguien ya después de copiar el manuscrito, porque se notan algunas correcciones hechas con la misma tinta (por ejemplo, hoja 93, donde la cifra 3 es corregida de la original 2).

$\mathrm{Al}$ pie de la pág. $88 \mathrm{~b}$ hay una anotación en ruso:

Въ сей рукописи нумерованныхъ листовъ двадцать четыре (24). Хр. Лопаревъ, 20 мая, 1909 г ('Este manuscrito contiene veinticuatro [24] hojas numeradas. C.[onservador] Loparev, 20 de mayo, 1909').

Esta anotación nos indica que J. M. Loparev, que era el conservador de documentos en escritura antigua rusa del Depósito de Manuscritos de la Biblioteca Imperial, consideraba que ésta era la última página del manuscrito. Supongo que Loparev no entendió las peculiaridades de la escritura del manuscrito que paginó. La cifra 8 es muy ancha y escrita de modo distinto a como lo hacen los rusos: el círculo superior está abierto y una parte de él se parece a la cifra 1 unida con un 6 (el círculo bajo). Pienso que ésta es la razón por la que Loparev pensó que se trataba de un 16 y consideró que la hoja 88 era 168, entonces la última, y en la que los conservadores escribían el número total de páginas.

Es interesante que el mismo Firkovitch entendiera correctamente la paginación. En su comentario escrito en hebreo sobre la carpeta del manuscrito dice:

24 hojas de papel en cuarto grande. 48 páginas de la página 83 hasta el fin de la 111. Parece que el l[ibro] hubiera sido grande en tamaño y desde el principio faltan 82 páginas y quién sabe cuántas más faltan de la 111 hasta el fin. Y está escrito en una bella escritura en letras hebreas sefardíes y en otro idioma, por eso el contenido de este libro es desconocido. 
El manuscrito es deficiente, le falta principio y final, y por eso no tenemos ni comienzo ni colofón y no sabemos el título original de la obra ni el nombre del autor. Tampoco sabemos si es una traducción, ni, en su caso, el nombre del traductor. Igualmente, nos falta información sobre la fecha de la copia y el nombre del copista.

El manuscrito fue comprado por Firkovitch durante sus viajes a Oriente Medio, y lógicamente debe ser originario de allí. Considerando las características de papel y escritura, pienso que el manuscrito fue elaborado en el Imperio otomano a principios del siglo XVIII.

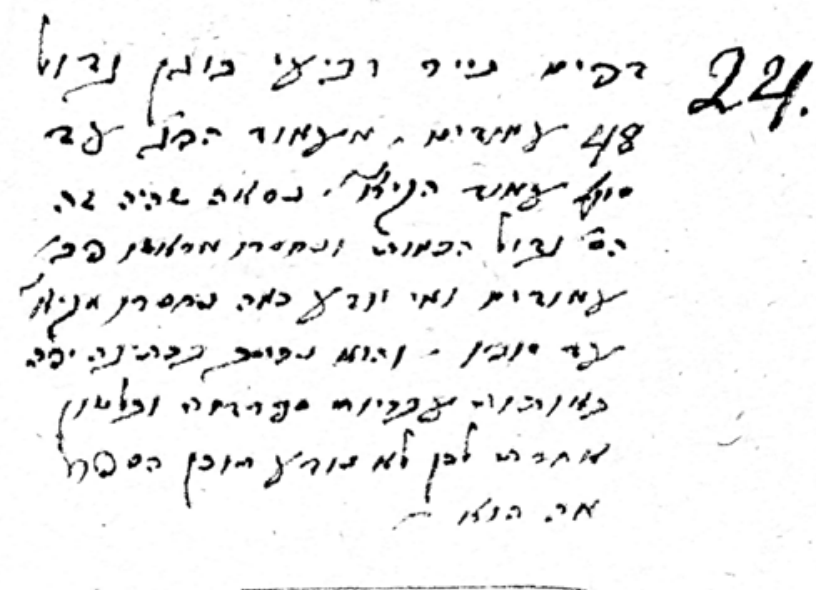

Fig. 1. Copia de la anotación con el comentario de Abraham Firkovitch en hebreo (sobre la carpeta del manuscrito).

PAPEL

El manuscrito está escrito en papel amarillento con tinta negra, un poco descolorida por el tiempo. Las hojas 83-88, 92-98, 105-106 tienen como filigrana un racimo de uvas con una corona. Además, en las hojas 93-98 hay una filigrana con la letra Q. Las uvas se parecen al número 2380 del catálogo Heawood ${ }^{12}$, pero por desgracia el catálogo no puede ayudar porque la entrada está marcada «N[o] P[lace], N[o] D[ate]»; esto es, sin lugar y sin fecha.

Mehmed Ali Kagitci, en su libro sobre la historia de la producción de papel en Turquía, menciona una filigrana semejante: «grapes with crown with or wi-

${ }^{12}$ Edward Heawood, Watermarks, mainly of the $17^{\text {th }}$ and $18^{\text {th }}$ centuries (Hilversum 1950), \# 2380, pág. 117, lám. 314. 
thout intials [sic] - paper printed in the printing house of Said Ahmed Celebi and Ibrahim Muteferrika» ${ }^{13}$. Si hubiera que dar crédito a Kagitci, el papel del manuscrito podría haber sido elaborado entre 1732 y 1750:

In 1732 printing was introduced in this country by Said Ahmed Celebi and Ibrahim Muteferrika. In order to meet the growing need of paper, the founders of the Turkish printing industry, Ibrahim Muteferrika and Said Ahmed Celebi, established a paper mill in the village of Elmalik near Yalova ${ }^{14}$.

Pero a pesar de su seudónimo, Kagitci (que significa 'el que produce papel') no merece mucha confianza. No sólo está su libro lleno de erratas, sino que incluye muchas afirmaciones que se pueden poner en cuestión, como por ejemplo la fecha de introducción de la imprenta en el Imperio otomano. Si el autor trata sólo de imprenta musulmana y productores de papel musulmanes (y esto no está indicado en su libro), tendría que saber que los judíos habían impreso libros en la Sublime Puerta muchos años antes de 1732. Existen incunables en hebreo impresos en Estambul (Constantinopla) por los judíos de origen hispánico. Antes de 1732, en el Imperio otomano había tipografías judías no sólo en la capital sino también en Salónica, Esmirna y algunas otras ciudades, y estas imprentas producían muchos libros, tanto en hebreo como en judeoespañol. Supongo que además de los judíos, los cristianos (griegos y armenios) imprimían sus libros antes de 1732. Además, todas las comunidades, incluso las que aún no usaban máquinas de imprenta, necesitaban papel para cuestiones legales, administrativas, sociales y personales. Vale la pena mencionar que la introducción de las imprentas no redujo el uso de manuscritos, ni siquiera entre los judíos. Como había demanda de papel, lógicamente tenían que satisfacerla, y bien fue importado bien producido localmente. Sin embargo, la historia de la producción de papel por parte de varias comunidades del Imperio otomano todavía no está investigada.

Me atrevo a suponer que el manuscrito que estamos investigando había sido escrito antes de 1732 y que el papel no es el fabricado por Celebi y Muteferrika. Según mi experiencia de trabajo con manuscritos y libros antiguos hebreos ${ }^{15}$, incluyendo los escritos en el Imperio otomano, el siglo XVIII marcó un cambio drástico en la calidad del papel en la Sublime Puerta. Si en otros países el papel se hizo

${ }^{13}$ Mehmet A. Kagrtci, Historical Study of Paper Industry in Turkey (Istanbul 1976), pág. 16.

${ }^{14}$ Kagitci, Historical Study of Paper Industry, pág. 10.

${ }^{15}$ Entre los años 2000-2002 trabajé en el departamento de libros raros de la biblioteca del YIVO - Institute for Jewish Research, catalogando libros publicados antes de 1750, entre ellos muchos impresos en Salónica, Estambul y Esmirna. 
más fino (o conservó la textura anterior), la calidad del papel producido en el Imperio otomano en el siglo XVIII es considerablemente peor en comparación con la del que habían usado los amanuenses y tipógrafos judíos locales en los siglos XVI-XVII. Los libros hebreos publicados en el Imperio otomano en el siglo XVIII están impresos en un papel muy grueso, con superficie áspera, con filigranas apenas discernibles, con el corte quebrado... supuestamente, el papel de Celebi-Muteferrika.

No obstante, el papel de nuestro manuscrito Evr. I 308 es muy fino y liso, casi transparente, con filigranas claras, con bordes rectamente cortados, de calidad considerablemente superior si la comparamos con la del papel usado por tipógrafos judíos otomanos en el siglo XVIII.

Cerca de los puntos hay algunos vestigios de agua, pero el texto no está dañado. La hoja 19 tiene algunos agujeros hechos por gusanos. El tamaño de la página es de 19 x 14,5 cm, y la caja de escritura mide 10,2 x $14 \mathrm{~cm}$. El texto está escrito en letras hebreas, en letra cursiva sefardí minúscula. La lengua no tiene nada que ver con el «dialecto caucáseo», como suponía Harkavy, sino que se trata de romance castellano escrito en letras hebreas.

\section{LETRA}

La escritura y el diseño del texto son típicos de otros manuscritos datados en el siglo XVII de la misma colección ${ }^{16}$. En cada página hay 21 líneas, con el reclamo (que en nuestra edición presentamos entre paréntesis angulares $<>$ ) escrito en la línea 22. Para preservar el tamaño del texto y observar los márgenes, el escribano usa varios métodos. A veces escribe letras muy anchas al final de la línea para ocupar todo el espacio, y otras veces hace letras muy estrechas para que toda la palabra quepa en la línea. Sin embargo, hay casos en que la palabra no cabe y entra en los márgenes. Asimismo, el amanuense utiliza muchas ligaduras, siendo las más habituales: álef / lámed; reš / álef; rě̌ / he; reš / vav; dálet / he; dálet / vav; y dálet / álef.

Los usos gráficos del texto corresponden a los habituales de la escritura judeoespañola aljamiada del siglo XVIII, en fase de transición. Así, todavía encontramos casos de vav utilizado para notar la consonante labiodental [v], alternando con los usos modernos de bet con tilde, como en vistió / ויסטייו, frente a alevantados / ליבנטאוס. Sin embargo, ya se distingue entre la prepalatal fricativa sonora [ž], notada con źayin con tilde en formas como hijá / איזיה o quis̀o / קיזו, mientras queda la guímal

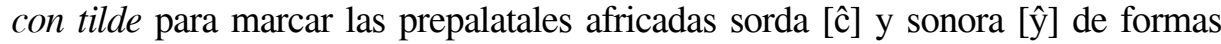

${ }^{16}$ Véase mi artículo sobre un manuscrito astronómico de la misma colección, «An Unknown Manuscript on Astronomy by Moshe Almosnino», en Hispano-Jewish Civilization After 1492, eds. M. Авiтbol, Y. T. Assis, G. Hasan-Rokem (Jerusalem 1997), págs. 41-54. 
como muncho / ג'ונטוס / מונג'ו y juntos respectivamente. Por otro lado, la notación del sonido consonántico palatal [y], se realiza siempre con lámed + doble yod, como vemos tanto en caballeros / קאביציירוס, como en ya / לייה.

Por lo general no hay vocalización diacrítica, pero cuando dos palabras semejantes aparecen juntas o en casos en que se supone que será difícil para el lector distinguir [e] o [i], el escribano usa el signo diacrítico seré para designar [e], dejando la yod sin signos para la [i].

El amanuense, que no es sistemático a la hora de notar la tilde diacrítica para distinguir, por ejemplo, pe / פ y fe / פ, comete a veces errores, escribiendo una palabra dos veces. Hay también otros lapsus calami. En muchas ocasiones, el escribano notó el error antes de terminar la palabra o inmediatamente después de terminarla y lo corrigió poniendo pequeñas rayas encima de la errata. La cantidad de estas erratas no significa que el escribano no fuese profesional. El texto no es sagrado, no hay reglas estrictas como, por ejemplo, para copiar la Torá. Además, es una novela de caballerías -tipo de lectura no aconsejado por los rabinos- y es lógico que el escribano no sea tan meticuloso. Parece que el manuscrito fue copiado no para la venta, sino para uso personal.

Los lapsus calami y sus correcciones nos indican que el manuscrito no es original sino una copia.

Los errores también indican que el amanuense sabía el idioma en que copiaba, el romance castellano. A veces había escribanos judíos que copiaban los textos mecánicamente: puesto que el alfabeto hebreo se usa para muchas lenguas habladas por judíos, en esos casos el copista hacía su trabajo sin entender lo que copiaba.

\section{Texto}

La novela está divida en capítulos. Como los capítulos no están numerados, ignoramos cuánto texto falta. La palabra capítulo está escrita con letras más grandes que el resto del texto y más parecidas a las letras hebreas cuadradas. A veces después de la palabra capítulo hay una explicación de su contenido, como un título, mientras que en otros lugares el texto sigue sin ninguna explicación. Así por ejemplo:

«CAPÍTULO bien se vos acodra cómo dej̄imos al enperador Brimardos» (pág. 83b, 13-14);

«CAPÍTULO bien vos acodra cómo deǰimos al buen infante don Lorenzo después que enṿió al nano Fomoźo» (pág. 87a, 19-21);

«Volỵió a dar su repuesta, la cual en el siguiente capítulo se dirá. CAPÍTULO diće la historia que luego que el mensajero se partió» (pág. 92b, 15-18). 
El contenido es típico de una novela de caballerías. Se trata de las aventuras del infante Don Lorenzo, que no conoce la identidad de sus padres y, aparentemente (pues faltan páginas para poder asegurarlo), los está buscando o, en cualquier caso, busca información acerca de ellos. Entretanto, se encuentra con varios gigantes y fieras, pelea con ellos y, lógicamente, los vence. El fragmento también trata de Brimardos, emperador de Tartaria, que, junto con veinte jóvenes caballeros, deja Constantinopla en busca de aventuras.

Las historias de amores -otro elemento típico de novelas de caballeríastambién están presentes. Cuatro doncellas se enamoran de Don Lorenzo: la doncella Sabatina, la hija del duque de Cales, la reina de Tesalia y la sabia Melindra (la última es, al mismo tiempo, reina de Escocia). Los fragmentos existentes describen escenas de amor entre Don Lorenzo y Sabatina, y también entre él y Melindra. Supuestamente, Lorenzo había hecho el amor antes con la hija del duque de Cales, pero esta parte de la novela falta. La reina de Tesalia, que también está enamorada del infante, le relata su historia. Ella se había casado con un tal Ribero, inicialmente una persona buena, pero que después se volvió traidor, mató al hermano de la reina, la encarceló y se casó con otra mujer que ahora está embarazada. La reina pide a Lorenzo que la vengue. Lorenzo, como un verdadero caballero que es, promete hacerlo. Él logra escapar de sus solicitudes amorosas explicando que no puede estar con ella mientras el marido, el traidor Ribero, esté vivo, pero le hace promesa de amarla una vez haya matado a su marido.

Como en cualquier novela de caballerías, hay muchas descripciones de batallas. Don Lorenzo pelea con tres jayanes; el rey de Tesalia lucha contra su cuñado Ribero y es vencido por él; Lorenzo lucha contra fieras feroces; el emperador Brimardos trata de vencer a los monstruos terribles, etc., etc.

La hechicería es otro elemento característico de este género literario. El texto abunda en descripciones de objetos hechizados (espadas y otras armas, cuernos, etc.) y de los milagros hechos por los sabios: el barco que navega el mar sin marineros, rica comida que aparece de la nada, el profundo sueño producido por el hechicero, etc. También hay animales y pájaros extraños que no existen en la vida real (centauros, fieras, etc.), enanos y gigantes.

Según los términos geográficos usados (Tesalia, Grecia, Berbería, Tartaria, Constantinopla, etc.) la novela pertenece al grupo de los libros de caballerías denominado por Pascual de Gayangos «ciclo greco-asiático» y así lo justifica:

Por cuanto los héroes fabulosos que le componen fueron principalmente emperadores de Constantinopla o reyes de Trapisonda, Macedonia, Tesalia, 
Jerusalén y Arabia. [...] la escena principal, el teatro de sus proezas y aventuras, es casi siempre en regiones asiáticas ${ }^{17}$.

Gayangos compara los ciclos bretón y carolingio de los libros de caballerías con los del ciclo greco-asiático y sostiene que los dos primeros tipos eran «exclusivamente franceses; el tercero fue engendrado en la Península por la brillante imaginación de nuestros escritores» ${ }^{18}$. De acuerdo con la definición de Gayangos, nuestra novela también es el fruto de la imaginación de un autor español. Los nombres geográficos corroboran esta suposición. Si hubiera sido creada en el Imperio otomano, el autor habría localizado las acciones en lugares más exóticos que Constantinopla. La capital del imperio, llamada por los judíos sefardíes «la famosísima ciudad», era familiar para ellos, al igual que Tesalia (Grecia), que era parte del Imperio otomano, con un gran porcentaje de población judía. Las novelas de caballerías pueden ser comparadas con libros de fantasía de hoy: las acciones en ambos casos acontecen en lugares exóticos.

Algunas inferencias indirectas indican que el texto no es una simple transliteración, sino una adaptación de una novela española para lectores judíos (si no una obra original). No hay curas ni monjes, sino sabios: sabia Melindra, sabio Bagamor y sabio Martirén. Nunca se mencionan símbolos cristianos como iglesias y cruces en carreteras. Además, hay algunas frases interesantes, como:

«cuando fue cativo en poder de Yisrael por mano de la profeta Šemuel» (pág. 108b, 18-19);

«aun-que sea la cueva de los muy falsos diośes de moros o de cristianos» (pág. 109b, 12-13);

«vente sacos de armas encantadas que el sabio Martirén había hecho para estos vente caballeros, para que con ellos haćer guera a toda la Cristiandad» (pág. 84b, 1-3);

«que por Dios verdadero en que tú crees, que en Él adoro yo también» (pág.104a, 16-17).

Estos ejemplos muestran que el texto fue, si no escrito, por lo menos adaptado por un judío.

También podemos observar algunos rasgos lingüísticos típicos del judeoespañol. En vez del verbo leer el escribano/autor usa solamente el verbo meldar («el enperador Brimardos meldó las letras» [pág. 85a, 9-10]).

\footnotetext{
${ }^{17}$ Pascual de Gayangos, Libros de caballerías, con un discurso preliminar y un catálogo razonado (Madrid 1857), pág. XXI.

${ }^{18}$ Gayangos, Libros de caballerías, pág.vi.
} 
En el plano fonético encontramos [m] en lugar de [n] como en muestro por nuestro o mośotros por nośotros; [g] en lugar de [v] como en güestro por vuestro); diferentes casos de metátesis como en acodro y tadró por acordo y tardó, respectivamente; porpóśito por propósito, dećilde por dećidle, etc.

Como en todos los manuscritos judeoespañoles, el escribano no siempre observa las reglas de ortografía, y tampoco sigue un modelo unívoco de representación gráfica. En muchos casos hay dos o más variantes de una palabra, que a veces encontramos en una misma página. Por ejemplo, en la pág. 109 encontramos dos formas distintas para notar la palabra ciprés: achiprés y achipréś.

A veces no se observa la concordancia en número y/o género entre adjetivos y sustantivos. En otros lugares falta el acuerdo entre los pronombres personales y las formas verbales o los pronombres posesivos. Tampoco hay consistencia en las formas de tratamiento: así, por ejemplo, la doncella Sabatina trata a Don Lorenzo tanto de tú como de vós.

Hasta aquí he proporcionado una breve descripción del manuscrito, cuyo texto no he podido atribuirlo a ninguna novela de caballería conocida. En vano he tratado de consultar varios especialistas norteamericanos, por lo que ahora me dirijo a quienes puedan ayudar en la identificación de la novela o por lo menos sugerir direcciones de futura investigación.

Anexo I. Edición de la primera página conservada (83a)

[... $]_{1}$ era buena hora del día y vido al nano Fomośo en pies. / Luego ${ }_{2}$ se alevantó y por mano del nano se vistió y se armó de sus ${ }_{3}$ armas; / y cuando quis̀o salir afuera de su apośento / halló a_los dos caballeros que ya había buena pieza que lo estaban ${ }_{5}$ esperando. / Y él se fue para la sala del castillo, / donde ${ }_{6}$ halló allí a su donćella que lo sacó de Ingle-tiera, / y los dos ${ }_{7}$ escuderos y al caballero anciano. / Y el nano Fomośo fue ${ }_{8}$ muy de prisa al apośento de su señora y la hiźo alevantar.

${ }_{9}$ Ella se alevantó lo más presto que pudo y hiźo poner ${ }_{10}$ meśa, y se desayunaron todos juntos con el tío del duque ${ }_{11}$ de Cales. / Y alevantados los manteles, / luego aḅajaron ${ }_{12}$ al patio del castillo / donde hallaron los caballos y los ${ }_{13}$ palafrenes prontos.

/ Y caballando en ellos / se partieron ${ }_{14}$ de_la donćella hija del duque, / que no dejaba de entre_sí de ${ }_{15}$ llorar y suspirar con la color de cara algo cortada. / Y ${ }_{16}$ despidiéndose de ella / tomaron el camino de Ingle-tiera. ${ }_{17}$ Y como se vido algo lejos de allí, se apeó debajo de un ${ }_{18}$ pino que en la floresta había, / y estuvo un rato allí. ${ }_{19}$ Que como le pareció tienpo, / dijo a_los dos caballeros que diesen ${ }_{20}$ las cartas al nano Fomośo, y que mirasen por él muncho ${ }_{21}$ en el camino; / y al nano le dijo: / «Tú, amigo, todas cuantas $<$ albircias $>[\ldots]$. 
क人

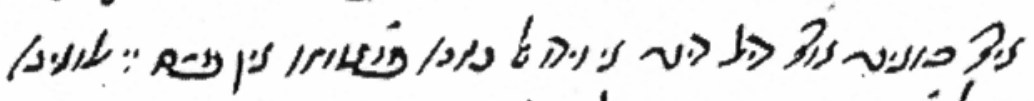

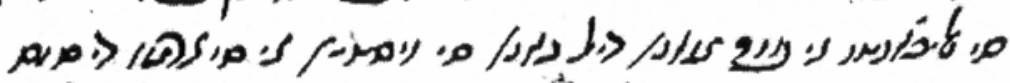

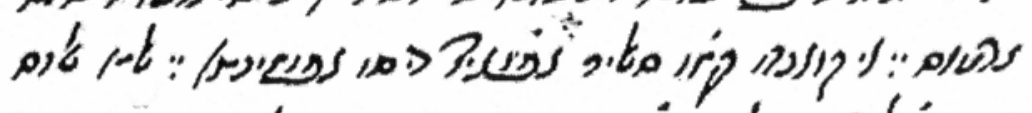
-

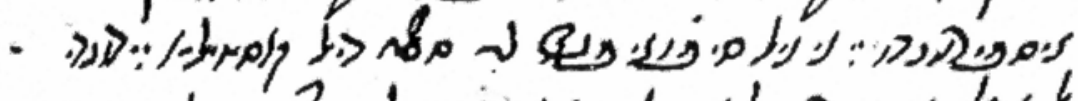
a)

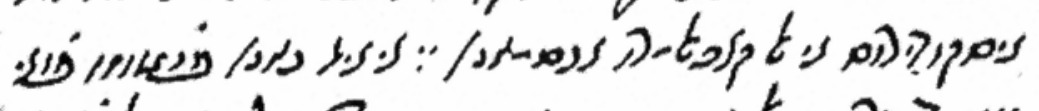

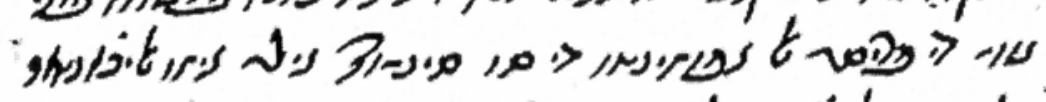

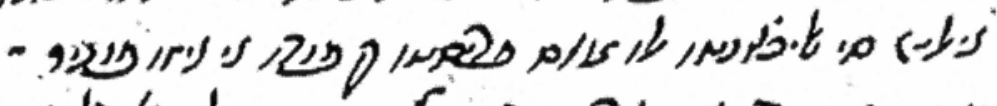

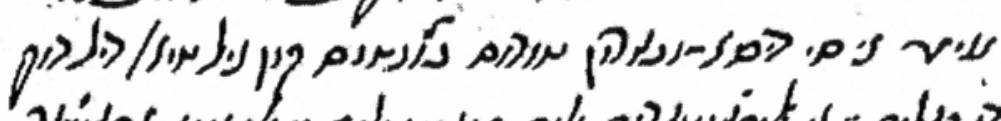

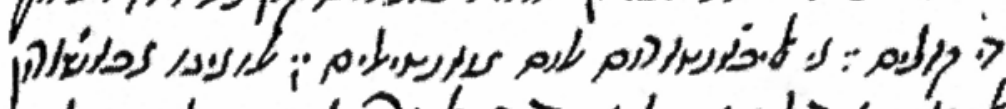

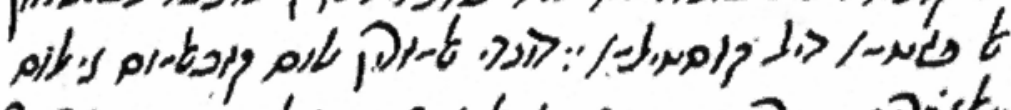

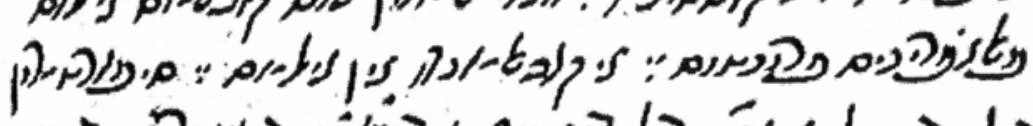

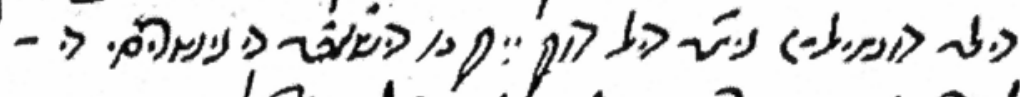

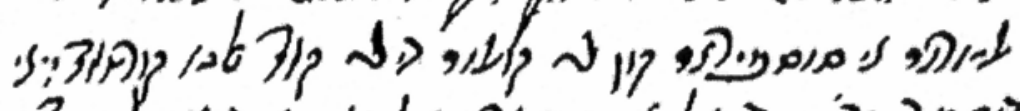

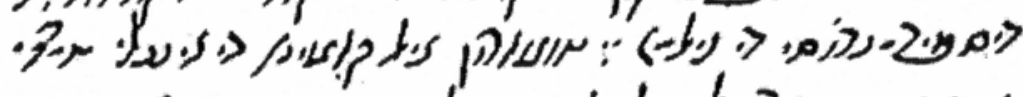

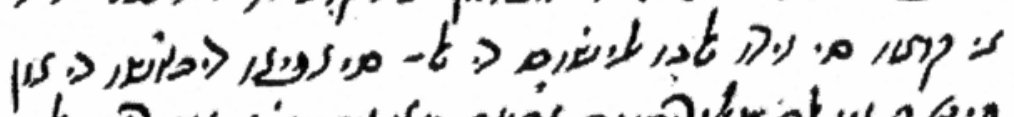

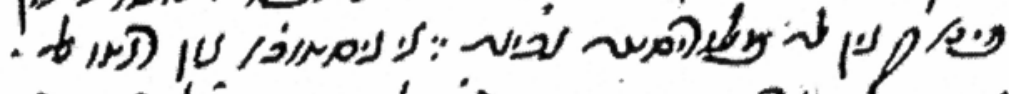
|

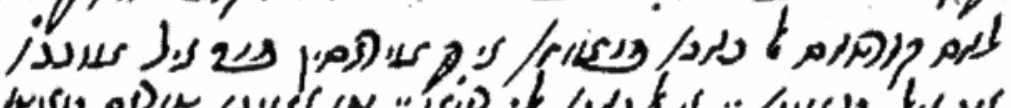

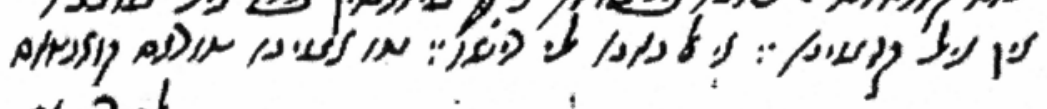
م-olol

Fig. 2. Copia de la primera página conservada del manuscrito (83a). 


\section{Anexo II. Lista de personajes citados}

El infante Don Lorenzo, de la corte del rey Pablán; su escudero, el nano Fomośo; el rey Pablán, el rey de Pmliquinos (sic); la reina de Tesalia y su marido, el traidor Ribero; su hermano, el rey; la doncella Sabatina; tres hermanos jayanes, primos de Ribero; la sabia Melindra, reina de Escocia, que puede convertirse en distintas cosas o fieras; el sabio Bagamor, padre de Melindra; el duque de Cales y su hija; el sabio Martirén, que vive en una cueva, y el emperador Brimardos de Tartaria

\section{Anexo III. Nombres geográficos citados}

Tesalia; Berbería (a través del mar de Tesalia, siete días de viaje por mar); Asia; Grecia; Constantinopla; Montes de la Muerte; Eropa (sic); Ingle-tiera (sic).

Recibido: $18 / 02 / 2008$

Aceptado: 01/08/2008 